\title{
EFEKTIVITAS PELATIHAN KETERAMPILAN KOMUNIKASI UNTUK MENINGKATKAN SELF-ESTEEM SISWA FLIGHT OPERATION OFFICER LEMBAGA TRAINING CENTER X
}

\author{
Ucu Anggraeni ${ }^{1}$, Riana Sahrani ${ }^{2}$ dan Soemiarti Patmonodewo ${ }^{3}$ \\ ${ }^{1}$ Fakultas Psikologi, Universitas Tarumanagara Jakarta \\ Email: ucu.anggraeni@gmail.com \\ ${ }^{2}$ Fakultas Psikologi, Universitas Tarumanagara Jakarta \\ Email: rianas@fpsi.untar.ac.id \\ ${ }^{3}$ Fakultas Psikologi, Universitas Tarumanagara Jakarta \\ Email: mimie_patmonodewo@yahoo.com
}

\begin{abstract}
ABSTRAK
Meningkatnya industri penerbangan saat ini harus diimbangi dengan peningkatan keselamatan. Faktor keselamatan tidak hanya dinilai dari jenis pesawat terbaru yang memiliki teknologi yang canggih, namun faktor penting lainnya ialah sumber daya manusia itu sendiri salah satunya flight operation officer (FOO). Seorang FOO wajib memiliki kompetensi, sertifikasi, dan mampu melakukan tugas sesuai standar dan aturan yang berlaku. Salah satu tugas utama FOO ialah memberikan informasi secara langsung yang disebut dengan briefing kepada pilot sebelum melakukan tugas terbang. Isi briefing tersebut ialah mengenai seluruh informasi penerbangan termasuk kondisi cuaca dan kondisi rute yang akan dilalui oleh pilot, sehingga apabila diperkirakan ada kondisi yang kurang aman dapat diambil tindakan-tindakan pencegahan. Namun pada kenyataanya masih terjadi tidak dilakukan briefing sesuai standar oleh FOO kepada pilot yang mengakibatkan terjadi kecelakaan pesawat dan menelan banyak korban meninggal. Tidak dilakukannya briefing salah satu penyebabnya dalah rendahnya self esteem individu untuk melakukan komunikasi interpersonal secara tatap muka. Penelitian ini bertujuan untuk mengetahui efektivitas pelatihan keterampilan komunikasi dalam meningkatkan self- esteem pada siswa flight operation officer (FOO) yang menggunakan metode intervensi dengan pelatihan. Tiga domain perilaku yang dikembangkan dalam suatu pelatihan menyasar pada aspek kognitif, afeksi, dan psikomotor. Penelitian ini dilaksanakan pada bulan September-Desember 2017. Partisipan penelitian terdiri dari 10 siswa kelompok eskperimen dan 14 siswa kelompok kontrol. Jumlah partispan kelompok eksperimen terdiri dari 1 perempuan dan 9 laki-laki, serta 3 perempuan dan 11 laki-laki pada kelompok kontrol. Penelitian ini menggunakan desain penelitian eksperimental dengan pretest-posttest control group design. Instrument pengumpulan data yang digunakan pada penelitian ini adalah Rosenberg Self-Esteem Scale (RSES) (Brown,1998) dan Komunikasi Interpersonal (Devito dalam Aw, 2011). Data dianalisis dengan teknik paired simple t-test dengan kriteria statistic non parametric Wilcoxon. Perhitungan dengan membandingkan skor pretest dan posttest RSES pada kelompok eksperimen dan kelompok kontrol. Hasil perhitungan diperoleh terdapat perbedaan yang signifikan antara pretest dan posttest dalam kelompok eksperimen, dikarenakan hasil yang diperoleh $<0.05$, yakni 0.000 $<0.05$. Hal ini menjelaskan bahwa terjadi peningkatan self-esteem pada siswa FOO di kelompok eksperimen yang berarti pelatihan Komunikasi Interpersonal efektif dapat meningkatkan Self-Esteem siswa FOO Training Center X. Apabila self esteem siswa tinggi maka siswa dapat melakukan komunikasi interpersonal yang efektif dan melakukan tugas briefing sesuai dengan standar yang berlaku.
\end{abstract}

Kata kunci: self-esteem, pelatihan komunikasi interpersonal, flight operation officer, penerbangan

\section{PENDAHULUAN}

Dalam dunia penerbangan di Indonesia agar suatu penerbangan dapat berjalan dengan lancar dan aman maka dibutuhkan orang-orang yang kompeten dan memiliki kualifikasi khusus dalam bidangnya masing-masing, khususnya flight operation officer (FOO) atau disebut juga captain on the ground. Pada saat pilot sampai bandara sebelum menuju ke pesawat, seorang pilot harus menuju ke ruang flight operations (FLOPS) untuk mendapatkan briefing dari FOO sebelum menuju ke pesawat dan melaksanakan tugas terbang. Ruang flops ini biasanya terdapat di area di dalam bandara atau tidak jauh dari bandara agar tidak membutuhkan waktu yang lama menuju ke pesawat. Briefing yang diberikan FOO kepada pilot menggunakan dispatch release form, form ini berisi informasi mengenai jenis pesawat, registrasi pesawat, jumlah crew, jumlah penumpang, 
jumlah bahan bakar, rute penerbangan, rute alternatif, parkir pesawat, perlengkapan pesawat yang dibawa, tipe penerbangan, perkiraan cuaca, berat pesawat dengan jumlah penumpang dan barang yang akan diangkut, dan lain sebagainya. Briefing ini diberikan FOO kepada pilot di ruang flops dilakukan di meja FOO dengan posisi FOO dan pilot berdiri berhadapan. Setelah briefing diberikan FOO kepada pilot maka dispatch release form akan ditanda tangani oleh FOO dan pilot sebagai tanda kedua belah pihak memahami dan menyetujui informasi yang diberikan menurut hasil wawancara dengan salah satu instruktur FOO di Training Center X. Tugas briefing ini merupakan salah satu kewajiban FOO kepada pilot sesuai dengan aturan pemerintah dalam Civil Avition Safety Regulation (CASR) 121.601, May 2017. Tugas briefing ini dijelaskan juga oleh Adi et.al., (2016) yaitu FOO akan melakukan penjelasan informasi atau yang disebut dengan istilah briefing kepada pilot sebelum penerbangan dilaksanakan. Setelah briefing dilakukan maka dilanjutkan dengan menandatangani dispatch release sebagai tanda bahwa rencana penerbangan sudah aman (safe), ekonomis, nyaman untuk penumpang dan disepakati oleh kedua belah pihak. Selanjutnya Adi et.al., (2016) menjelaskan bahwa setelah pesawat mengudara, FOO juga memantau penerbangan untuk memberikan bantuan kepada pilot jika diperlukan serta memberikan informasi perkembangan cuaca atau informasi penting lainnya. Pemantauan ini dilakukan terus menerus sampai pesawat mendarat dan misi penerbangan dianggap selesai, kemudian FOO akan melakukan briefing kembali dengan pilot untuk perencanaan penerbangan berikutnya.

Petugas FOO haruslah berlisensi atau memiliki sertifikat atau licence apabila melakukan tugas dan tanggung jawabnya sesuai dengan Peraturan Menteri Perhubungan nomor: KM 16 Tahun 2010 tentang Peraturan Keselamatan Penerbangan Sipil Bagian 63 Tentang Persyaratan Personel Pesawat Udara Selain Penerbang dan Personel Penunjang Operasi Pesawat Udara, maka lembaga pendidikan FOO harus yang ditunjuk oleh pemerintah melalui Direktorat Kelaikan Udara dan Pengoperasian Pesawat Udara (DKUPPU) dan telah lulus audit. DKPPU akan mensertifikasi lembaga training tersebut sehingga dapat menyelenggarakan training untuk FOO. Salah satu lembaga pelatihan yang telah mendapat izin atau approval dari Kementerian Perhubungan adalah Training Center X. Berdasarkan data yang diperoleh dari web site Lembaga Pelatihan X, pada tahun 1994 yang merupakan awal terbentuknya Training Center X dan diresmikan oleh Menteri Perhubungan pada tahun 1995, serta memperoleh approval dari DKUPPU.

Salah satu tugas briefing ini wajib diberikan FOO kepada pilot, namun hal ini pernah menjadi masalah bahwa diduga ada oknum pilot yang mengambil data cuaca dari internet dan bukan dari FOO. Hal ini diungkapkan mantan Menteri Pehubungan Ignasius Jonan berdasarkan data dari National Geographic Indonesia pada bulan Januari 2015 menekankan agar briefing langsung perlu dilakukan supaya ada pembicaraan dan diskusi antara FOO dan pilot terkait dengan penerbangan yang akan dijalankan, termasuk tentang cuaca. Jika dari laporan cuaca terdapat situasi tertentu yang harus dicermati, FOO dapat memberi saran tentang rute atau ketinggian yang dilewati. Jadi tidak dibenarkan apabila pilot tidak mendapatkan briefing dari FOO mengenai informasi persiapan penerbangan. Berita lain mengenai penekanan briefing langsung antara pilot dan FOO dari Menteri Perhubungan Ignasius Jonan diperoleh dari website beritasatu.com pada Januari 2015 yang mengkaitkan kecelakaan pesawat Airasia QZ8501 yang menewaskan seluruh penumpangnya yang berjumlah 155 tersebut, salah satu faktornya adalah tidak dilakukannya briefing antara pilot dan FOO. Laporan akhir Komite Nasional Kecelakaan Transportasi (KNKT) mengenai kecelakaan pesawat udara jenis Sukhoi RRJ-95B; 97004 yang menabrak Gunung Salak di Jawa Barat pada tanggal 9 May 2012 yang menewaskan seluruh penumpang dan kru pesawat dengan total jumlah korban 45 orang. Salah satu temuan dan faktor yang berkontribusi dilaporkan oleh KNKT pada kecelakaan tersebut bahwa pilot tidak mendapatkan informasi yang cukup mengenai area 
penerbangan yang akan dilalui pilot sebelum terbang, sehingga pilot tidak cukup informasi mengenai area tersebut yang berakibat pilot tidak dapat segera melakukan tindakan yang tepat pada saat peringatan muncul dari sistem yang ada di pesawat dan pesawat menabrak Gunung Salak.

Dalam melakukan briefing ini maka seorang FOO harus memiliki keterampilan dalam berkomunikasi. Komunikasi yang dilakukan antara FOO dengan pilot pada saat briefing adalah komunikasi langsung secara tatap muka. Salah satu bentuk komunikasi yang sesuai dengan kondisi ini yaitu komunikasi interpersonal. Hal ini sesuai dengan yang dikemukakan (Indriyo Gitosudarmo dan Agus Mulyono dalam Suranto AW, 2011) komunikasi interpersonal yaitu komunikasi yang berbentuk tatap muka, interaksi orang ke orang, dua arah, verbal dan non-verbal, serta saling berbagi informasi dan perasaan antara individu dengan individu atau antar individu di dalam kelompok kecil. Komunikasi interpersonal merupakan bentuk komunikasi yang paling efektif dalam mengubah sikap, opini dan perilaku komunikan dibandingkan dengan bentuk-bentuk komunikasi lainnya. Akibat ketidakmampuan melakukan komunikasi interpersonal, individu cenderung menarik diri dan melakukan tindakan agresif, sulit menyesuaikan diri, mudah marah, cenderung memaksakan kehendak, egois, dan ingin menang sendiri sehingga mudah terlibat perselisihan. Komunikasi interpersonal yang baik setidaknya memiliki lima indikator yaitu keterbukaan (openness), empati (empathy), sikap mendukung (supportiveness), sikap positif (positiveness), dan kesetaraan (equality) menurut DeVito (2009). Beberapa faktor yang sangat menentukan keberhasilan komunikasi interpersonal apabila dipandang dari sudut komunikator yaitu dalam hal ini FOO yang akan memberikan briefing kepada pilot, yaitu kredibilitas, daya tarik, kemampuan intelektual, integritas atau keterpaduan sikap dan perilaku dalam aktivitas sehari-hari, keterpercayaan, kepekaan sosial, kematangan tingkat emosional, berorientasi kepada kondisi psikologis, dan bersikap supel, ramah, dan tegas (Aw, 2011).

Agar dapat terwujud komunikasi interpersonal yang efektif, seorang FOO harus memiliki selfesteem yang tinggi, agar penilaian terhadap diri sebagai individu yang memiliki banyak potensi dan kreativitas untuk dikembangkan, sehingga dirinya selalu terstimulasi untuk melakukan perubahan dan perkembangan kearah yang lebih baik. Self-esteem merupakan penilaian individu terhadap dirinya sendiri secara keseluruhan dari persepsinya mengenai perasaan berharga atau tidak berharganya. Cloutte (2001) memaparkan bahwa individu dengan self-esteem yang tinggi akan memandang dunia secara positif, dunia sebagai tempat yang baik dan kondusif untuk hidup, menilai diri sebagai individu yang memiliki banyak potensi dan kreativitas untuk dikembangkan, sehingga dirinya selalu terstimulasi untuk melakukan perubahan dan perkembangan kearah yang lebih baik. Apabila FOO memiliki self-esteem yang rendah maka FOO akan sulit untuk melakukan komunikasi interpersonal yang efektif karena belum dapat menghargai dirinya secara positif. Cloutte (2001) mendefinisikan bahwa self-esteem yang rendah yaitu memandang kehidupan secara negatif, selalu merasa tertekan, putus asa atau tidak ada harapan, berpikir bahwa dirinya buruk, dan tidak memiliki kualitas diri yang baik, sehingga selalu menyalahkan dirinya saat orang lain tidak ingin berteman dengannya. Self-esteem mengacu pada sikap individu, baik positif maupun negatif terhadap dirinya secara keseluruhan (Rosenberg, Schooler, Schoenbach, \& Rosenberg, 1995). Self-esteem memberikan pengaruh terhadap tingkat kenyamanan seseorang terhadap pengalaman berkomunikasinya jika seseorang pernah merasakan gagal dalam komunikasi di sebuah situasi atau peran tertentu, individu mungkin akan mengkaitkan hal-hal yang negatif dengan situasi atau peran tersebut (Pearson et al., 2011).Namun kenyataannya self-esteem yang dimiliki siswa FOO rendah dan siswa berada pada masa transisi perkembangan diri menuju remaja.

Siswa FOO yang berusia 18 hingga 24 tahun berada pada masa transisi perkembangan diri remaja menuju dewasa ini berbeda dari tahap perkembangan yang lain (Arnett, 2008). Terjadi berbagai 
perubahan pada masa remaja ini juga seringkali berdampak pada menurunnya rasa self-esteem pada diri remaja (Rhodes et.al, 2004). Hasil penelitian dari beberapa tokoh menunjukkan bahwa self-esteem cenderung mengalami penurunan ketika seseorang menginjak masa remaja (Robins et.al, 1999). Simmons dan Rosenberg (Brown, 2008) juga mendukung pernyataan tersebut dengan menyatakan bahwa remaja cenderung memiliki self-esteem yang rendah dan memiliki persepsi yang negatif terhadap penilaian orang lain terhadap diri mereka. Temuan lain mengatakan bahwa self-esteem merupakan masalah yang penting pada masa remaja karena self-esteem yang rendah pada seseorang remaja merupakan prediktor munculnya permasalahan pada masa dewasa (Simpson-Scott, 2009).

Menurut Bloom (Hutahaean, 2012), sasaran belajar yang efektif dapat meliputi tiga elemen perilaku yang akan diubah, yaitu sasaran kognitif, sasaran afektif, dan sasaran psikomotor. Metode intervensi yang mencakup perubahan pada ketiga elemen tersebut ialah training atau pelatihan. Metode intervensi dengan pelatihan untuk meningkatkan self-esteem yang sesuai dalam penelitian ini yaitu dengan pelatihan komunikasi interpersonal.

Hasil penelitian Wulansari, Hardjajani, \& Nugroho, (2013) menyatakan terdapat hubungan yang signifikan antara komunikasi yang efektif dan harga diri. Setiap meningkatnya komunikasi yang efektif dan harga diri, individu mampu menyampaikan pemikiran maupun perasaannya dengan cara yang tepat dan dapat menjadikan individu yang lain memahami, menyetujui, bahkan mengikuti apa yang disampaikannya dikarenakan minimnya kesalahpahaman yang muncul sebagai konsekuensi tercapainya efektivitas komunikasi yang dibangun. Hasil penelitian lainnya adalah yang dilakukan oleh Adi et.al., (2016) yang mengukur kepuasan pilot dan co-pilot terhadap kinerja FOO dan memperoleh hasil yang signifikan bahwa tingkat kualitas kerja FOO sudah baik dari hasil tersebut diperoleh melalui beberapa faktor yang dimasukkan diantaranya kemampuan FOO dalam berkomunikasi, FOO bersikap baik, ramah, sopan, FOO memberikan kondisi yang nyaman pada saat berkomunikasi dengan pilot, oleh sebab itu penelitian ini bertujuan untuk mengetahui apakah intervensi pelatihan keterampilan komunikasi efektif untuk meningkatkan selfesteem siswa FOO Training Center X.

\section{METODE PENELITIAN}

Partisipan dalam penelitian ini adalah siswa FOO Training Center X, di daerah Jakarta. Pada penelitian ini, partisipan harus memenuhi kriteria-kriteria yang telah ditetapkan, yaitu (a) siswa tamatan SMA atau sederajat; (b) usia 18-24 tahun; (c) merupakan siswa FOO yang masih aktif; dan (d) bersedia mengikuti intervensi yang dilakukan peneliti secara berkelompok dalam bentuk pelatihan. Total keseluruhan siswa FOO di Training Center X dalam satu kelas di penelitian ini berjumlah 24 orang, namun jumlah sampel penelitian yang digunakan dalam penelitian 10 orang berdasarkan hasil pre-test kuesioner self-esteem yang tergolong rendah. Penelitian ini diawali dengan proses pengumpulan data menggunakan kuesioner self-esteem. Sesuai jumlah partisipan yaitu 10 partisipan yang berada dalam kategori rendah, maka masuk dalam kelompok eksperimen. Peneliti kemudian membuat rancangan intervensi yang dituangkan dalam sebuah modul. Modul yang dibuat berisi rancangan program intervensi berupa pelatihan untuk siswa FOO. Modul diantaranya menjelaskan mengenai self-esteem yaitu lebih dalam mengenai pentingnya memiliki self-esteem yang tinggi bagi seorang FOO serta dampaknya apabila seorang FOO memiliki selfesteem yang rendah dan komunikasi interpersonal mengenai komponen-komponen komunikasi, proses dan tujuan komunikasi serta komunikasi yang efektif dikaitkan dengan pentingnya tugas 
briefing yang merupakan salah satu tanggung jawab FOO. Intervensi dilakukan sebanyak 16 sesi dalam 10 kali pertemuan. Pelaksanaan program intervensi dilakukan setelah kelas berakhir. Kelompok kontrol yang diambil dari siswa FOO dari kelas lain berjumlah 14 orang. Penelitian ini merupakan penelitian yang bersifat eksperimental dengan desain dua kelompok yang disertai pretest dan post-test, yaitu disebut juga dengan pre-test post-test group design.

Instrumen ukur dalam penelitian ini terdiri dari dua bentuk, yaitu berupa kuesioner dan observation checklist. Kuesioner yang digunakan adalah kuesioner self-esteem dari Rosenberg dan hasil penilaian dari instruktur Training Center X pada siswa untuk mengukur komunikasi interpersonal pada saat simulasi di ruang simulator berupa angka. Nilai awal yang diberikan instruktur Training Center X kepada siswa dilakukan sebelum mendapatkan intervensi dan nilai akhir yang diberikan oleh instruktur Training Center X setelah mendapatkan intervensi dari peneliti. Kuesioner selfesteem yang digunakan merupakan kuesioner self-esteem dari Rosenberg, yang berisi 10 butir pernyataan, terdiri dari 5 (lima) butir negatif dan 5 (lima) butir positif. Alat tes Rosenberg digunakan karena mengukur self-esteem secara global, berfokus kepada penilaian seseorang terhadap dirinya sendiri, tanpa merujuk pada suatu kualitas atau atribut yang spesifik (Brown, 1998).

Berdasarkan hasil face validity diperoleh nilai reliabilitas alat ukur alat ukur self-esteem dengan nilai Alpha Cronbach $(\alpha=0.743)$ dan jumlah pernyataan butir yang gugur dari hasil uji validitas menggunakan Product Momen Pearson Corelation sebanyak 3 butir, yaitu butir 3, 4, dan 8 dengan nilai $\mathrm{r}$ tabel sebesar 6.319. Sebagai data pendukung pengukuran dan evaluasi, peneliti menggunakan observation checklist dan lembar evaluasi program pelatihan. Observation checklist meliputi karakteristik dan indikator yang sama dengan dimensi komunikasi interpersonal.

Dalam penelitian ini komunikasi interpersonal diukur dengan menggunakan hasil penilaian pra simulator dan hasil simulator yang dilakukan oleh instruktur Training Center $\mathrm{X}$ dan peneliti hanya melakukan observasi. Siswa FOO sebelum dilakukan pengujian dalam melakukan briefing kepada pilot telah menyelesaikan materi-materi pelatihan FOO di dalam kelas atau ground training yang diberikan oleh Training Center X, sehingga pada saat pengujian briefing yang akan dilakukan satu per satu, siswa telah memahami apa isi briefing atau apa yang harus disampaikan oleh siswa FOO kepada pilot sesuai dengan tugas dan tanggung jawabnya serta menggunakan lembaran dispatch release form. Dalam mengukur komunikasi interpersonal pra simulator siswa FOO dalam kelompok eksperimen, salah satu instruktur Training Center X memberikan pengarahan mengenai prosedur briefing yang harus dilakukan kepada pilot sesuai dengan salah satu tugas dan tanggung jawab FOO, kemudian siswa satu per satu diminta melakukan tugas briefing tersebut kepada instruktur yang berperan sebagai pilot yang akan melakukan tugas terbang. Setelah semua siswa melakukan praktek kemudian instruktur Training Center X memberikan nilai pada setiap siswa, penilaian yang diberikan berdasarkan dispatch release form yang merupakan isi dari briefing.

\section{HASIL DAN PEMBAHASAN}

Uji normalitas penelitian menggunakan uji Saphiro-Wilk dikarenakan jumlah sampel yang kecil yakni $\mathrm{N}<200$ sampel. Uji normalitas bertujuan untuk mengetahui apakah data penelitian berdistribusi normal atau tidak. Uji normalitas terhadap skor total self-esteem pada kelompok eksperimen menunjukkan nilai sebesar 0.101 bahwa data terdistribusi normal. Distribusi dianggap normal jika nilai distribusi yaitu nilai $\mathrm{p}>0.05$ atau $0.101>0.05$. Demikian pula uji normalitas pada kelompok kontrol, skor total self-esteem yang menunjukkan nilai sebesar 0.122 data terdistribusi normal. Pada variabel self-esteem mempunyai nilai sig $(\mathrm{p})=0.122>0.05$, maka data 
skor total dikatakan terdistribusi normal, maka pada penelitian ini digunakan paired sample t-test untuk uji perbedaan hasil pre-test dan post-test dengan rincian hasil seperti terlihat pada Tabel 1.

Tabel 1.

Gambaran Self Esteem Pada Kelompok Eksperimen \& Kelompok Kontrol

\begin{tabular}{lcc}
\multicolumn{1}{c}{ Variabel } & $\begin{array}{c}\text { Paired Sample T- } \\
\text { Test (mean) }\end{array}$ & Sig. (2 tailed) \\
\hline Self-Esteem (pre-test) Kelompok Eksperimen & 24.3 & 0.000 \\
\hline Self-Esteem (post-test) Kelompok Eksperimen & 34.8 & 0.000 \\
\hline Self-Esteem (pre-test) Kelompok Kontrol & 28.7 & 0.317 \\
\hline Self-Esteem (post-test) Kelompok Kontrol & 29.7 & 0.317 \\
\hline
\end{tabular}

Hasil uji paired sample t-test diperoleh adanya perbedaan nilai rata-rata pada pre-test dan posttest dalam kelompok eksperimen. Nilai pre-test cenderung lebih rendah dari nilai post-test. Dengan demikian dapat disimpulkan bahwa terjadi peningkatan self-esteem pada siswa FOO di kelompok eksperimen setelah mendapatkan pelatihan. Sedangkan pada kelompok kontrol menunjukkan ada perbedaan nilai rata-rata pada pre-test dan post-test dalam kelompok namun tidak terlalu signifikan hanya berbeda satu poin saja, dikarenakan kelompok kontrol tidak mendapatkan treatment apapun agar hasil perbedaan lebih meyakinkan. Berdasarkan data tersebut bahwa dapat disimpulkan bahwa tidak terjadi peningkatan self-esteem yang signifikan pada siswa FOO di kelompok kontrol.

Perolehan data untuk komunikasi interpersonal diberikan oleh instruktur Training Center X adalah berdasarkan dispatch release form yang merupakan lembaran yang berisi beberapa informasi yang harus dijelaskan oleh FOO kepada pilot sebelum melakukan tugas terbang. Dispatch release form tersebut diberikan sebelum intervensi pelatihan komunikasi interpersonal pada materi sebelum komunikasi interpersonal diberikan dan setelah materi komunikasi interpersonal diberikan. Nilai $<70$ kategori kurang, nilai $<80$ kategori cukup, dan nilai $\geq 80$ kategori baik. Data nilai yang diperoleh siswa FOO pada kelompok eksperimen secara rinci dapat dilihat dalam tabel berikut:

Tabel 2.

Hasil Nilai Pre-test dan Post-test Komunikasi Interpersonal Siswa FOO Kelompok Eksperimen

\begin{tabular}{ccccc}
\hline \multirow{2}{*}{$\begin{array}{c}\text { No. } \\
\text { Eartisipan Kelompok }\end{array}$} & $\begin{array}{c}\text { Komunikasi Interpersonal } \\
\text { (Briefing to pilot) }\end{array}$ & Gain Score \\
\cline { 3 - 4 } & Pre-test & Post-test & \\
\hline 1 & IS & 60 & 75 & 15 \\
\hline 2 & SS & 65 & 80 & 15 \\
\hline 3 & SJ & 60 & 75 & 15 \\
\hline 4 & NF & 65 & 85 & 10 \\
\hline 5 & MF & 60 & 70 & 10 \\
\hline 6 & MS & 68 & 85 & 17 \\
\hline 7 & MK & 65 & 90 & 25 \\
\hline 8 & RW & 65 & 85 & 20 \\
\hline 9 & NH & 65 & 85 & 20 \\
\hline 10 & FA & 60 & 80 & 20 \\
\hline
\end{tabular}




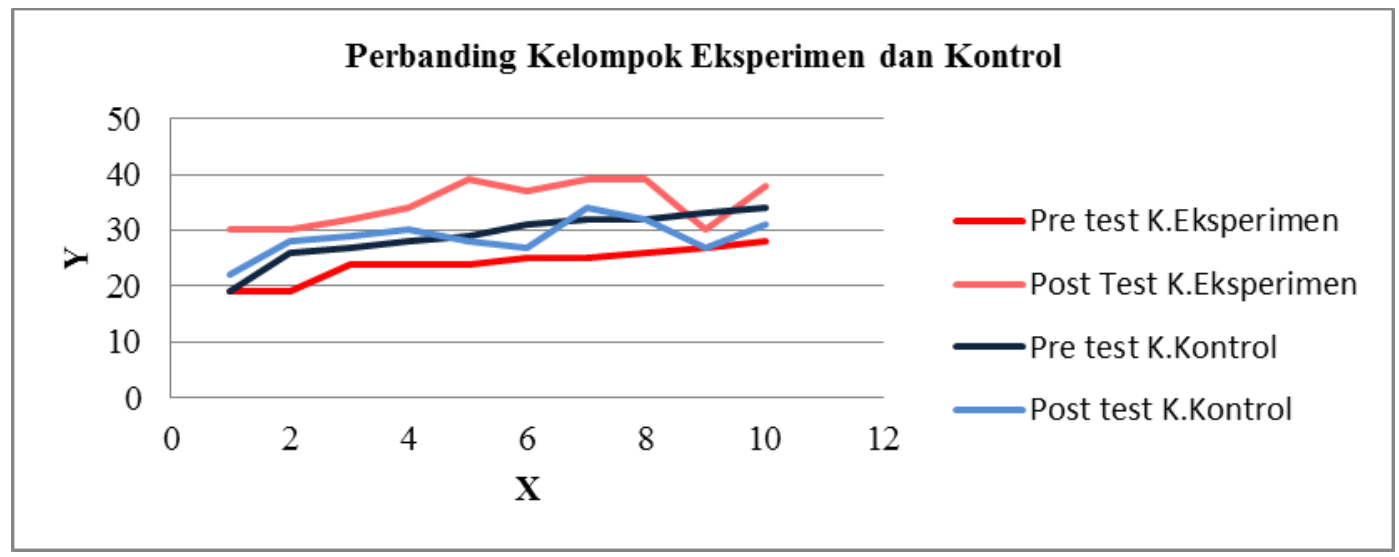

Grafik 1. Perbandingan kelompok eksperimen dan kelompok kontrol

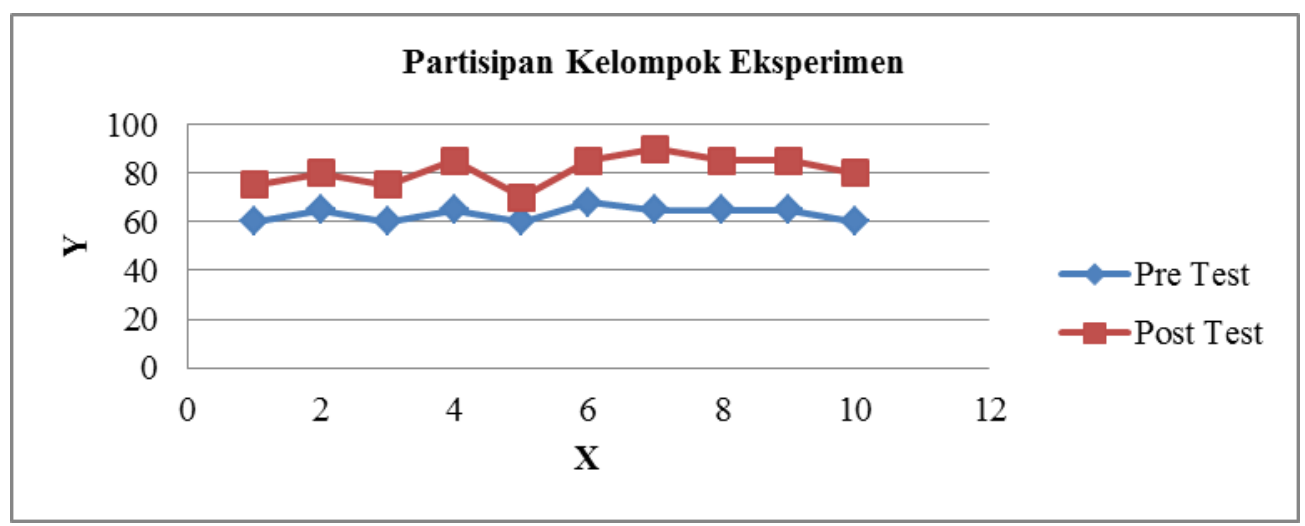

Grafik 2. Perbandingan pre-test dan post-test kelompok eksperimen

\section{KESIMPULAN DAN SARAN}

Dalam penelitian ini ditemukan bahwa pelatihan komunikasi interpersonal efektif meningkatkan self-esteem pada siswa FOO Training Center X. Hal ini berarti bahwa pelatihan komunikasi interpersonal efektif meningkatkan self-esteem siswa FOO sehingga dirinya menjadi lebih berharga dan mampu melakukan briefing sesuai dengan prosedur dan dispatch release form. Merasa ketidakberhargaan diri siswa, memandang diri rendah, merasa tidak mampu, merasa diri tidak akan berhasil yang dialami oleh sepuluh siswa partisipan dapat diperbaiki dengan pelatihan komunikasi interpersonal ini.

Hal ini sesuai dengan hasil penelitian Wulansari et.al.,(2013) menyatakan terdapat hubungan yang signifikan antara komunikasi yang efektif dan harga diri. Setiap meningkatnya komunikasi yang efektif dan harga diri, individu mampu menyampaikan pemikiran maupun perasaannya dengan cara yang tepat dan dapat menjadikan individu yang lain memahami, menyetujui, bahkan mengikuti apa yang disampaikannya dikarenakan minimnya kesalahpahaman yang muncul sebagai konsekuensi tercapainya efektivitas komunikasi yang dibangun. Hasil penelitian lainnya adalah yang dilakukan oleh Adi, et.al., (2016) yang mengukur kepuasan pilot dan co-pilot terhadap kinerja FOO dan memperoleh hasil yang signifikan bahwa tingkat kualitas kerja FOO sudah baik dari hasil tersebut diperoleh melalui beberapa faktor yang dimasukkan diantaranya kemampuan FOO dalam berkomunikasi, FOO bersikap baik, ramah, sopan, FOO memberikan kondisi yang nyaman pada saat berkomunikasi dengan pilot. 
Melalui penelitiannya pada tahun 2002 , Twenge dan Crocker (Mruk, 2006) mengelompokkan etnis-etnis tertentu yang memiliki tingkat self-esteem tertinggi hingga terendah, yakni: Blacks, Whites, Hispanics, American Indians, dan Asians. Menurut mereka, terdapat empat hal yang dapat menjelaskan perbedaan tingkat self-esteem pada masing-masing etnis dengan latar belakang kultur dan budaya tertentu. Peneliti menyarankan agar penelitian selanjutnya dapat melakukan penelitian lebih lanjut mengenai faktor budaya di Indonesia apakah berpengaruh terhadap self esteem FOO.

Penelitian ini diharapkan dapat memberikan informasi bagi individu yang sedang berada pada jenjang sekolah menengah tingkat atas agar dapat mengelola ataupun meningkatkan self-esteem, tidak hanya dalam bidang penerbangan namun juga dalam bidang akademik, untuk mengoptimalkan pencapaian prestasi belajar yang lebih sempurna untuk ke jenjang pendidikan selanjutnya ataupun lingkungan pekerjaan yang ingin diraih. Dengan persaingan hidup yang semakin ketat, dibutuhkan kesadaran untuk lebih mempersiapkan diri, agar dapat ikut serta berkompetisi dengan mengandalkan kemampuan diri sendiri.

Upaya penting lainnya yang dapat dilakukan adalah dengan melakukan review, perbaikan, maupun penyusunan kurikulum yang sesuai dengan kebutuhan peserta didik, baik siswa FOO maupun siswa lainnya. Hal ini disebabkan karena pada dasarnya peserta didik yang merupakan siswa FOO, tentunya memiliki waktu, kebutuhan, kapasitas dan metode pembelajaran dan penilaian yang berbeda dengan siswa regular atau non FOO. Selain itu program pelatihan dan bimbingan juga mempunyai andil yang penting dalam keberhasilan belajar siswa FOO di training center X. Pelatihan untuk meningkatkan self-esteem peserta didik, khususnya siswa FOO juga dapat dilaksanakan secara berkesinambungan dan memperbanyak materi mengenai self-esteem. Tingkat penguasaan materi peserta didik yang bervariasi, maka bantuan seperti bimbingan, mutlak diperlukan kepada anak didik yang bermasalah. Dalam hal ini, peran guru BK berkaitan dengan social support yang dapat diberikan dalam bentuk bimbingan konseling saat siswa FOO merasa menemukan hambatan, atau hanya sekedar dapat menjadi teman bicara untuk menyelesaikan masalah. Dengan demikian, mereka dapat lebih tenang dan merasa mendapat dukungan karena adanya perhatian untuk meningkatkan semangat belajarnya. Usaha tersebut perlu dipertahankan dan tidak dibatasi dengan hanya penanganan oleh guru BK (Bimbingan Konseling), akan tetapi wali kelas atau instruktur lainnya juga dapat ikut berperan dalam hal ini.

\section{Ucapan Terima Kasih (Acknowledgement)}

Terima kasih kami ucapkan kepada Training Center X yang mengizinkan kami untuk mengambil data dan melaksanakan pelatihan. Terima kasih juga kami ucapkan untuk seluruh partisipan penelitian yaitu para instruktur, staf, dan pihak manajemen yang sudah memberikan izin.

\section{REFERENSI}

Agustine, P. F. (2015, Januari 6). Jabatan Flight Operation Officer (FOO) Belakangan Sering Disebut Sejak Peristiwa Jatuhnya Pesawat Airasia QZ 8501 Di Perairan Selat Karimata. Diambil tanggal 14 September 2017, dari http://www.beritasatu.com/sains.html.

Al'ain, O. M. \& Mulyana, P. O. (2013). Pelatihan Asertif Untuk Meningkatkan Komunikasi Interpersonal HIMA (Himpunan Mahasiswa) Prodi Psikologi FIP UNESA. Jurnal Psikologi Universitas Surabaya, 02(01). 
Astianingrum, Y. (2013). Bimbingan Teman Sebaya Untuk Meningkatkan Komunikasi Interpersonal Siswa. Artikel Jurnal. Universitas Sebelas Maret Surakarta.

Aw, S. (2011). Komunikai Interpersonal. Yogyakarta. Graha ilmu.

Cloutte, P. (2001). How To Increase Your Self-Esteem. London: Mind Publications.

Duffy, K.G., \& Atwater, E. (2002). Psychology for Living: Adjustment, Growth, and Behaviour Today ( $7^{\text {th }}$ ed.). New Jersey: Pearson Education, Inc.

Tidak ada penulis, (2015, Januari 4). Surat Menhub Jonan dan Pilot Senior Terkait Aksi Marah Besar Di Airasia. Detik News.. Retrieved from https://news.detik.com

Devito, A. J. (2011). Komunikasi Antar Manusia (5th ed.). Tangerang Selatan: Karisma Publishing Group.Erol. Y. R. \& Orth, U. (2011). Self-Esteem Development From Age 14 to 30 Years: Longitudinal Study. Journal of Personality and Social Psychology. University of Basel, 101(03), 607-609.

Guindon, M. H. (2010). Self-Esteem Across The Lifespan: Issues and Interventions: USA: Taylor and Francis Group, LLC.

Gumaryadi, E. (2015, Januari 7). Apa Saja Tugas Flight Operation Officer. Diambil tanggal 14 September 2017, dari https://beritasatu.tv.html.

Gunawan \& Poerwanto, E. (2015). Analisis Beban Kerja Mental Pekerja Bagian Ground handling Bandara Adisutjipto Untuk Mendukung Keselamatan Penerbangan. Jurnal Angkasa, 7(2).

Heryadi, A. \& Widyayanti, N. (2015). Efektifitas Pelatihan Komunikasi Interpersonal Untuk Meningkatkan Kemampuan Komunikasi Interpersonal Siswa SMA. Jurnal Psikologi Mandiri Sekolah Tinggi Psikologi Yogyakarta.

Hutahaean, B. S. H. (2012). Pelatihan Untuk Peningkatan Self -Esteem Pada Mahasiswa Universitas Indonesia Yang Mengalami Distress Psikologis. Tesis. Universitas Indonesia. Kamaruzzaman, (2016). Analisis Keterampilan Komunikasi Interpersonal Siswa. Jurnal Konseling Gusjigang, 2(2). IKIP PGRI Pontianak,

Kesitawahyuningtyas, T. M. \& Padmomartono, S. (2014). Meningkatkan Komunikasi Interpersonal Melalui Layanan Bimbingan Klasikal Pada Siswa Kelas X SMA Negeri I Getasan, Kabupaten Semarang. Jurnal Universitas Kristen Satya Wacana, 30(2), 63-70.

KNKT, (2012). Aircraft Accident Investigation Report (Sukhoi RRJ-95B; 97004). 7 Agustus 2017. Retrieved from http://www.knkt.dephub.go.id/webknkt/investigasi_report.php.

Larasati, P. W. (2012). Meningkatkan Self Esteem Melalui Metode Self-Instruction. Tesis. Universitas Indonesia.

Mruk, C. J. (2006). Self Esteem Research, Theory, and Practice: Toward a Positive Psychology of Self-Esteem (3rd ed.). New York: Springer Publishing Company, Inc.

Ningrum, R. P. R. (2015). Upaya Meningkatkan Komunikasi Interpersonal Melalui Teknik Konseling Kelompok Pada Siswa Kelas VII B SMP Negeri 1 PAKEM. E-Journal. Universitas Negeri Yogyakarta.

Pahrudin, C., Chandra, A., \& Warsito, T. (2016). Kepuasan Kapten Pilot Dan Co Pilot Terhadap Kinerja Flight Operation Officer. Jurnal Manajemen Bisnis Transportasi Dan Logistik. STMT Trisakti. 2(3).

Pramudiastuti, W. (2012). Pengaruh Pelatihan Pengenalan Diri Terhadap Harga Diri Pada Anak Kelas V Di Sekolah Dasar Negeri Glagah Umbulharjo Kota Yogyakarta. Naskah Publikasi. Sekolah Tinggi Ilmu Kesehatan 'Aisyiyah Yogyakarta.

Pratiwi, W. S. \& Sukma, D. (2013). Komunikasi Interpersonal Antar Siswa Di Sekolah Dan Implikasinya Terhadap Pelayanan Bimbingan Dan Konseling. Jurnal Ilmiah Konseling, 2(1), 324-329.

Rakhmat, J. (2014). Metode Penelitian Komunikasi. Bandung. Remaja Rosdakarya. 
Ramaraju, S. (2012). Psychological Perspectives On Interpersonal Communication. Journal of Arts, Science \& Commerce.

Republic Of Indonesia Ministry Of Transportation. (2017). Civil Aviation Safety Regulation (CASR). Part.121

Restuti, N., Machmuroch, \& Hakim, A. M. (2015). Pengaruh Pelatihan Pengenalan Diri Terhadap Peningkatan Harga Diri Remaja Panti Asuhan Pamardi Yoga Surakarta. Jurnal Psikologi. Universitas Sebelas Maret.Rohmah, A. F. (2012). Pengaruh Pelatihan Harga Diri Terhadap Penyesuaian Diri Pada Remaja. Jurnal Psikologi Universitas Ahmad Dahlan.

Rosenberg, M., Schooler, C., Schoenbach, C., \& Rosenberg, F. (1995). Global Self-Esteem and Specific Self-Esteem: Different Concepts, Different Outcomes. American Sociological Review. 60(1), 141.

Sapril, (2011). Komunikasi Interpersonal Pustakawan. Jurnal Iqra', 5(1).

Seniati, L., Yulianto, A., \& Setiadi, B.N. (2017). Psikologi Eksperimen (edisi 4). Indeks

Simahate, T. (2013). Penerapan Komunikasi Interpersonal Dalam Melayani Pengguna Perpustakaan. Jurnal Iqra', 7(2).

Siska, Sudardjo, \& Purnamaningsih, H. E. (2003). Kepercayaan Diri Dan Kecemasan Komunikasi Interpersonal Pada Mahasiswa. Jurnal Psikologi. Universitas Gadjah Mada, 2, 67-71.

Sukmana, Y. (2015). Begini jawaban Menteri Perhubungan Terhadap Surat Terbuka Pilot, dilihat 7 Agustus 2017. <http://nationalgeographic.co.id>

Vieira, M. A., Santos, C. I., \& Kubo, M. K. E. (2014). Communication And Behaviour In High Reliability Organizations: An Analysis of Communication In Civil Aviation. Bussiness Journal. 3(7), 1-15.

Wibowo, B. S. (2016). Benarkah Self Esteem Mempengaruhi Prestasi Akademik. Jurnal Psikologi Indonesia, 13(1), 72-83.

Widodo, S. A. \& Pratitis, T. N. (2013). Harga Diri Dan Interaksi Sosial Ditinjau Dari Status Sosial Ekonomi Orang Tua. Jurnal Psikologi Indonesia. Universitas 17 Agustus 1945 Surabaya, 2(2). 131-138.

Wulansari, H., Hardjajani, T., \& Nugroho, A. A. (2013). Hubungan Antara Komunikasi Yang Efektif Dan Harga Diri Dengan Kohesivitas Kelompok Pada Pasukan Suporter Solo Sejati (Pasoepati). Jurnal Psikologi. 